\title{
Unpaved road verges as hotspots of fleshy-fruited shrub recruitment and establishment
}

\author{
AlbertoSuárez-Esteban a,*,MiguelDelibes a ,JoséM.Fedriani a,b \\ ${ }^{a}$ Departamento de Biologíadela Conservación,EstaciónBiológicadeDoñana(CSIC),AméricoVespucios/n,41092Sevilla,Spain \\ ${ }^{\mathrm{b}}$ Department of EcologicalModelling, HelmholtzCentreforEnvironmentalResearch GmbH-UFZ, Permoserstrasse 15, 04318Leipzig, Germany
}

Keywords:

Colonization

Conservation

Corridors

Hedgerows

Reforestation

Steppingstones

\begin{abstract}
A B S T R A C T
Hypothetical low-quality habitats can hold an overlooked conservation value. Some frugivorous mammalssuchastheredfox( Vulpesvulpes) and theEuropean rabbit( Oryctolaguscuniculus ) dispersemany viable seeds of fleshy-fruited shrubs along the verges of soft linear developments (SLD), such as trails and firebreaks. However, seedarrivaldoesnotguaranteeplantrecruitment, sinceseveralpost-dispersal processes can alter seed rain. To examine whether SLD verges assist shrub recruitment and establishment, we compared the density and the structure of a community of Mediterranean shrubs between SLDverges and the adjacentscrubland.

Bothseedlingsandadultfleshy-fruited shrubsdispersedby foxesandrabbitsreachedhigherdensities alongSLDvergesthaninthescrubland,suggestingSLDvergescanbesuitablehabitatsforshrubrecruitmentand establishment. Bird-dispersed shrubs showed a similar pattern, whereas shrubs dispersed by ungulatesandbadgers( Melesmeles )aswellasrockroses( Cistaceae)showedsimilardensitiesinbothhabitats. Shrub species compositionand diversity were similar between habitats.

Due toa marked differential seed arrival,SLDverges housed higher densities offleshy-fruited shrubs than the adjacentscrubland.Established shrubs may attractseed-dispersing wildlife, and create proper environments for plant recruitment, generating a reforestation feedback. Incipient shrub populations alongroadsidesmayactassteppingstoneswithpotentialtoconnectisolatedpopulationsinfragmented landscapes, whereSLDarepervasive. Werecommend carefulmanagementoffrugivorepopulationsand SLDverges in order to favor the diversity and the structural complexity of nativevegetation while preventing thespread of invasivespecies.
\end{abstract}

\section{Introduction}

Plantsaresessileorganismsthatrelyonpollenandseedvectors fordispersal.Thespatialdistributionofseeds(i.e.seed rain)influences the spatial and genetic structures of plant populations and communities,andalsodeterminesplantcolonizationability(Howe and Miriti, 2000; Nathan and Muller-Landau, 2000; Wang and Smith,2002).Seed rainoftendependsontheinteractionbetween seed vectorsandlandscapestructure(Damschenetal.,2008). For example, wind-dispersed species will be further dispersed in open-windy compared to dense-windless habitats (Bacles et al., 2006). Moreover, the presence of certain features (e.g. a forest edge) can promote seed accumulation associated with them (Nathan and Katul, 2005). In the case of endozoochores (plants whose seeds are dispersed in animal interiors), the preferential use of certain structures or habitats by frugivores can also result

\footnotetext{
* Correspondingauthor.Tel.:+34954466700x1155; fax:+34954621125.

E-mailaddress: asuarez@ebd.csic.es(A.Suárez-Esteban).
}

instrongseedclustering.Forexample,birdsand monkeysdeposit mostseedstheyingestunderneathperches, roostsandnests(Harvey,2000; HerreraandGarcía,2009; Russoetal.,2006; Shielsand Walker,2003).

However, seed arrival does not guarantee plant recruitment (Gómez-Aparicio, 2008; Hampe et al., 2008). Whether seed dispersal foci such as isolated trees (Herrera and García, 2009), windbreaks (Harvey, 2000), perches (Shiels and Walker, 2003) and resting sites (Russo et al., 2006) lead to plant recruitment and establishment (Wenny, 2001) or, conversely, they become propagule sinks (Hille Ris Lambers and Clark, 2003; Spiegel and Nathan, 2010), has paramount importance for plant diversity (Ozinga et al., 2009), population dynamics (Howe and Miriti, 2000) and ecosystem functioning (Isbell et al., 2011). Wherever seed concentration actually leads to enhanced recruitment, dispersal foci become hotspots of plant colonization(Wenny,2001), withahugepotentialforimprovingreforestationsuccess(Brederveld et al., 2011) and plant diversity conservation (Ozinga et al., 2009). In particular, pervasive natural or human-made structures 
that receiveseeds and alsofacilitate plant recruitmentand establishment should becarefully considered in reforestation and conservation programsworldwide.

Identifyingsuccessfulplacesforplantrestorationrequiresadetailedevaluationofseedarrivalandseedlingrecruitment(Hampe, 2011; Sagnardetal.,2007).Forexample,somestudieshavefound thatexperimentallinearclearingsofforestcanenhancebird-mediatedseeddispersal(Leveyetal.,2005;Tewksburyetal.,2002)and that thisseed corridoreffectimprovesconnectivity, whichinturn promotes plant diversity at differentscales(Damschen and Brudvig,2012; Damschenetal.,2006).Inthesameline,arecentstudy inSWSpain(Suárez-Estebanetal.,2013)hassuggestedthatpervasive human-made structures devoid of vegetation, such as trails and firebreaks (called "soft linear developments"; hereafter SLD), canactasseedreceptorsfornativefleshy-fruitedshrubs,especially forthosedispersedbyrabbits( Oryctolaguscuniculus )andredfoxes (Vulpes vulpes ), which positively select SLD verges for defecation (Suárez-Esteban et al., 2013). However, whether such disproportionate seed arrival along SLD leads to an enhanced local woody species recruitment and establishment is unknown for any study system.

AlthoughSLDcanreceiveaconsiderableamountofanimal-dispersed seeds, they could also represent an ecological trap ( sensu Schlaepferetal.,2002)ifmostofthoseseedsfailtoestablish.Seed accumulation can lead to increased density-dependent mortality (Spiegel and Nathan, 2010), either at the seed (e.g.post-dispersal seed predation;Hulme,1997)orattheseedlingstage(e.g.herbivory, nutrient competition, water stress, trampling; Hille Ris Lambers and Clark, 2003). Therefore, assessing whether pervasive structures such as SLD verges are not only seed dispersal foci but alsosuitablehabitatsforwoodyplantrecruitmentcouldbecritical to understand the dynamics of natural shrub regeneration and plantdiversityin human-dominatedlandscapes.

In this study, we quantified for the first time the density and diversityofalargecommunityofMediterraneanshrubscomposed ofbothdry-fruitrockroses( Cistaceae)andfleshy-fruited shrubsin relation to SLD. Whereas there are no reasons to think that seed rain of rockroses should be modified by the presence of SLD, an earlier study indicated that the seed rain of fleshy-fruited species varied in relation to SLD, as a consequence of the fecal marking behavior of their main dispersal vectors (Suárez-Esteban et al., 2013). Considering the importance of seed rain in shaping spatial patterns of plant recruitment (Howe and Miriti, 2000), we expected to find a concordance between shrub densities and the mainhabitatusedfordefecationbytheirmainseeddispersalvectors.Thisis:(1)higherdensitiesoffleshy-fruited shrubsdispersed by rabbits and foxes (which defecated mainly along SLD verges; Suárez-Esteban et al., 2013) along SLD verges than in the scrubland.Contrary,weexpectedtofind(2)theoppositepatternforfleshy-fruited shrubs dispersed by ungulates and badgers ( Meles meles; which defecated mainly in the scrubland; Suárez-Esteban et al., 2013), and (3) similar rockrose densities along SLD verges and the scrubland, given their lack of specific dispersal mechanisms(BastidaandTalavera,2002).

Becausepost-dispersalprocesses(i.e.seed predation,droughts, herbivory,etc.)couldaltertheseedtemplate(Fedrianietal.,2012; Gómez-Aparicio, 2008), we also expected (4) a stronger concordance between seed rain and the density of seedlings of fleshyfruited shrubs than regarding saplings and adult shrubs. Finally, given that fleshy-fruited shrub seed rain varied in intensity but not in species diversity in relation to SLD (Suárez-Esteban et al., 2013),weexpected(5)nodifferencesinthediversityofneitherfleshy-fruited shrubs nor rockroses between SLD verges and the scrubland.

This study provides evidence and a basis for assessing the potential of SLD to recruit native shrubs, as well as the influence of suchpervasivelandscapefeaturesonplantcolonizationandestablishmentspatial patterns.

\section{Materialandmethods}

\subsection{Studyareaandspecies}

Thequantificationofshrubabundanceanddiversitywascarried outduringthespring(March-April)of2011intheDoñanaNational Park(SWSpain;37 ${ }^{\circ} 9^{\prime} \mathrm{N}, 6^{\circ} 26^{\prime} \mathrm{W} ; 510 \mathrm{~km}^{2}$; elevation0-80m).This area contains several ecosystems (e.g., marshland, scrubland, dunes) and a vast (over $2000 \mathrm{~km}$ ) SLD system composed of dirt tracks(62.5\%)andfirebreaks(35.5\%).TheDoñana'sscrublandharborsadiverseandspatiallyvariablecommunityofnativeMediterranean shrubs. To encompass most shrub species present in the area, we chose the same three sites sampled by (Suárez-Esteban et al., 2013), which are separated from each other by $2.5-14 \mathrm{~km}$ and are called "Reserva", "Rocina" and "Matasgordas". "Reserva" is covered by pine woods and a dense Mediterranean scrubland dominated by dry-fruit rockroses (Cistaceae), such as Cistus libanotis, Halimium calicinum, Halimium halimifolium, and gorses (Stauracanthus spp.).Ithasalsoa relativehigh presence offleshyfruitedspeciessuchas Juniperusphoenicea subsp. turbinata, Phillyrea angustifolia and Rubus ulmifolius (overall density is $0.14 \pm 0.03 \mathrm{shrub} / \mathrm{m}^{2}$; mean $\pm \mathrm{SE}$ ). "Rocina" is a riparianwoodland zone surrounded by Mediterranean scrubland and croplands. The scrublandareacomprisesscattered Pinuspinea withadenseunderstoryof Cytisusgrandiflorus, H.halimifolium , and Stauracanthus spp. Fleshy-fruitedplantssuchas Asparagus spp., Oleaeuropaea var. sylvestris, Osyrisalba, and R.ulmifolius arepresentbutscarce(overall density $0.07 \pm 0.02 \mathrm{shrub} / \mathrm{m}^{2}$ ). "Matasgordas" is characterized by anopenMediterraneanwoodlanddominatedbyscattered Fraxinus angustifolia, Quercussuber, withpatchesofrockrosessuchas Cistus salvifolius and H.halimifolium with a variable extension, and a diverseanddensecommunityoffleshy-fruitedplantssuchas Chamaerops humilis, Daphne gnidium, Myrtus communis, P. angustifolia, Pistacia lentiscus, Pyrus bourgaeana, Rhamnus oleoides and Rubia spp. (overalldensity $0.42 \pm 0.08 \mathrm{shrub} / \mathrm{m} \quad{ }^{2}$; forfurtherdetailsconcerningthestudyareasee(Suárez-Estebanetal.,2013).

InDoñanamostofthesefleshy-fruitedspeciesflowerduringlaterwinterandspring(February-May)andproducedrupes(e.g., $\quad P$. lentiscus, R.ulmifolius )orberries(e.g., M.communis )thatripenduring August-December (Fedriani and Delibes, 2009a; Jordano, 1984).Dependingonthespecies,eachfruitcontainsgenerallyfrom onetoeightseeds,though R.ulmifolius fruitscancontainmorethan 20 seeds (Jordano, 1995). They are mainly dispersed by birds and mammals (Fedriani and Delibes, 2009b, 2011; Jordano, 1984). Rockroses flower in April-June and their seed release mechanism consists basically in the dehiscenceand fragmentation of thecapsules containing many small seeds (Bastida and Talavera, 2002). Though these plants have no long-distance dispersal adaptations, theyhaveconsiderablecolonizationability,especiallyindisturbed and burned habitats (Guzmán and Vargas, 2009). They are occasionally dispersed by ungulates(MaloandSuarez,1996).

Suárez-Estebanetal.(2013)found that theseed rainoffleshyfruited shrubs varied near and away from SLD, depending on the fecalmarkingbehavioroftheirmaindispersalvectors.Specifically, 79.49\% ( $N=13,066$ ) of J.phoenicea, P.angustifolia and R.ulmifolius seedswasdispersedalongSLDverges, mostlybytheEuropeanrabbitandtheredfox.Contrary,88.91\%( $\quad N=451)$ of Asparagus spp., C. humilis and P.lentiscus seedswasdispersedinthescrubland(away fromSLD), mostlybytheEurasianbadger,thereddeer Cervuselaphus,thefallowdeer Damadama andthewildboar Susscrofa (boar and both deer species will be subsequently referred to as “ungulates"). 


\subsection{Samplingdesign}

Ineachofour threestudy sites, we setup two 500m transects alongSLDvergesand two paralleltransectsof thesamelengthlocated60mawayfromSLD,inthescrubland.Alongeachtransectin MatasgordasandReserva, wesampledfifteen(12m $\quad{ }^{2}$ )plotsplaced equidistantly (around $27 \mathrm{~m}$ apart), where we counted all fleshyfruitedshrubsaswellasallrockroses(i.e. Halimium spp.and Cistus spp.).IntheRocinasite,weproceededinthesamewayexceptthat wesurveyeddouble-sizedplots $\left(24 \mathrm{~m}^{2}\right)$ tooffsetthelocallowdensities of fleshy-fruited shrubs. We controlled for plot size in all analysestoenablemeaningfulamong-sites comparisons.

Weclassified fleshy-fruited shrub speciesinto threefunctional groupsaccording totheirmaindispersalvectorsinourstudysites (Table 1):(1)species whose seeds are mostly dispersed by rabbit andfox,(2)specieswhoseseedsaremostlydispersedbyungulates andbadger,and(3)speciesthatinDoñanaaremostlydispersedby birds(according to(Jordano 1984,1995). Rockroses were used as control species because they have not any dispersal mechanism (BastidaandTalavera,2002).

Furthermore, we measured the height, and the maximum and minimumdiameter(theirproductestimates thevolumeoccupied by each individual) of every fleshy-fruited shrub within the sampling plots. Shrubs were then classified into three size classes: seedlings(plantswithcotyledonsand/orwithavolumelowerthan $100 \mathrm{~cm}^{3}$ ), adults(plantswithflowers, fruitsortheirremainsand/or withavolumehigherthan $8.5 \mathrm{~m}^{3}$ ), andsaplings(plantsoutsidethe othercategories).Duetologisticlimitations,rockrosescouldnotbe measuredandthuswereexcludedfromsomeanalyses(seebelow).

\subsection{Statisticalanalyses}

Toassesswhetherrecruitmentandestablishmentinrelationto SLDvariedaccordingtoshrubdispersalvector, wedeterminedthe combined influence of habitat(SLD verges vs.scrubland)and dispersalvectorsinthedensityofbothfleshy-fruitedshrubsandrockroses.Weusedthenumberofshrubsfound perplot(standardized by using the plot area as offset variable) as the response variable with habitat,dispersalvectorand theirinteractionasfixedfactors in a generalized linear mixed model (GLMM) with negative binomial distribution (which was more appropriate than Poisson distribution for our zero-inflated count data; Quinn and Keough, 2002) and log-link function (by means ofSAS 9.2 glimmix procedure; Littelletal.,2006).

Wealsoevaluated theeffectofSLDonthesizestructureof the threefunctionalgroupsoffleshy-fruitedshrubs.Todoso,wefitted aGLMMwithnegativebinomialdistributionandlog-linkfunction withthenumberoffleshy-fruitedshrubsfoundperplot(standardized by plot area as above) as the response variable, and habitat, dispersalvector,sizeclassandtheirsecond-andthird-orderinteractionsasfixedfactors.

Inourmixedmodels, siteandplot(nestedwithinsite)wereincludedasrandomfactorstocontrolforenvironmentalheterogeneity. For interactions, we tested the effect of one factor on the differentlevels of the other factor("tests of simplemain effects") using the SLICE option in the LSMEANS statement (Littell et al., 2006).Adjusted means and standard errors werecalculated using theLSMEANSstatement,whichestimatesthemarginalmeansover abalanced population.

To characterize shrub community structure in relation to SLD, we built two matrices (one for fleshy-fruited shrubs and one for rockroses)with the number of shrubs found perplot of each speciesconsideringallsizeclasseswithineach habitat. Weevaluated thesimilaritiesintheplantcommunitybetweenthehabitatsusing theADONISprocedure(permutationalmultivariateanalysisofvariance using distance matrices) in the VEGAN package (Oksanen et al., 2012). It was performed in R.2.15.0 ( $R$ development core team,2012)with9999permutationsand thepairwiseBray-Curtis approximation(BrayandCurtis, 1957).Inthefleshy-fruited shrub matrixweremovedthreeplotsfromtheanalysisduetoabsenceof anyshrubspecies.ADONISreportsa $P$-valueestimatedbyrepeated permutations of the data(Oksanenetal.,2012)thatindicates potential differences in shrub species composition and diversity betweenhabitats.

\section{Results}

\subsection{Influence ofdispersalvectorsonshrubdensity and community structureinrelationtoSLD}

We found fleshy-fruited shrubs and rockroses in $49.4 \%$ and $93.89 \%$ of the sampled plots ( $\quad n=180$ ), respectively. Overall, we

Table 1

Mean ( \pm SE) density of each shrub taxa per plot $\left(12 \mathrm{~m} \quad{ }^{2}\right.$ ) along SLD verges and $60 \mathrm{~m}$ away in the scrubland. The major dispersal vector of each taxa - selected based on the references provided below-isshown.

\begin{tabular}{|c|c|c|c|c|}
\hline Plants & SLDverges & Scrubland & Dispersalvector & References \\
\hline \multicolumn{5}{|l|}{ Fleshy-fruitedshrubs } \\
\hline Asparagus spp. & $0.32 \pm 0.09$ & $0.67 \pm 0.30$ & Ungulate & Suárez-Estebanetal.(2013) \\
\hline Pistacialentiscus & $0.23 \pm 0.11$ & $0.20 \pm 0.06$ & Ungulate & Suárez-Estebanetal.(2013) \\
\hline Myrtuscommunis & $0.03 \pm 0.02$ & $0.18 \pm 0.12$ & Ungulate & Suárez-Estebanetal.(2013) \\
\hline Chamaeropshumilis & $0.17 \pm 0.07$ & $0.36 \pm 0.18$ & Badger & Suárez-Estebanetal.(2013),FedrianiandDelibes(2011) \\
\hline Pyrusbourgaeana & $0.10 \pm 0.09$ & $0.08 \pm 0.06$ & Badger & Suárez-Estebanetal.(2013),FedrianiandDelibes(2009b) \\
\hline Rubia spp. & $1.01 \pm 0.46$ & $0.27 \pm 0.25$ & Birds & Jordano $(1984,1995)$ \\
\hline Osyrisalba & $0.44 \pm 0.32$ & $0.33 \pm 0.23$ & Birds & Jordano $(1984,1995)$ \\
\hline Rhamnusoleoides & $0.30 \pm 0.10$ & $0.29 \pm 0.09$ & Birds & Jordano(1984,1995) \\
\hline Daphnegnidium & $0.27 \pm 0.10$ & $0.11 \pm 0.06$ & Birds & Jordano $(1984,1995)$ \\
\hline Oleaeuropaeasylvestris & $0.02 \pm 0.02$ & $0.02 \pm 0.02$ & Birds & Jordano $(1984,1995)$ \\
\hline Tamuscommunis & $0.01 \pm 0.01$ & $0.00 \pm 0.00$ & Birds & Jordano $(1984,1995)$ \\
\hline Juniperusphoeniceaturbinata & $0.60 \pm 0.19$ & $0.13 \pm 0.07$ & Rabbit/Fox & Suárez-Estebanetal.(2013) \\
\hline Phillyreaangustifolia & $0.87 \pm 0.36$ & $0.43 \pm 0.18$ & Rabbit & Suárez-Estebanetal.(2013) \\
\hline Rubusulmifolius & $0.08 \pm 0.05$ & $0.01 \pm 0.01$ & Fox & Suárez-Estebanetal.(2013) \\
\hline \multicolumn{5}{|l|}{ Rockroses } \\
\hline Halimium halimifolium & $10.14 \pm 1.33$ & $9.79 \pm 1.13$ & None & BastidaandTalavera(2002) \\
\hline Halimium calicinum & $3.18 \pm 0.59$ & $3.44 \pm 0.47$ & None & BastidaandTalavera(2002) \\
\hline Cistussalvifolius & $0.90 \pm 0.37$ & $0.87 \pm 0.27$ & None & BastidaandTalavera(2002) \\
\hline Cistuslibanotis & $0.29 \pm 0.10$ & $1.92 \pm 0.47$ & None & Bastidaand Talavera(2002) \\
\hline Cistuscrispus & $0.07 \pm 0.04$ & $0.00 \pm 0.00$ & None & Bastidaand Talavera(2002) \\
\hline
\end{tabular}


located 678 fleshy-fruited shrubs belonging to 14 species (Table 1 ), with $59.14 \%$ and $40.86 \%$ of individuals found within SLD and scrubland plots, respectively. Rockroses were more abundant but less diverse than fleshy-fruited shrubs. Overall, we found 2754 individuals belonging to only five rockrose species (Table 1), with $47.64 \%$ located within SLD plots and $52.36 \%$ within scrubland plots.

As predicted, the dispersal vector affected the distribution of shrubs in relation to SLD (interaction Habitat*Dispersal vector; $F_{3,623}=4.70 ; P<0.01$ ). Whereas the density of rockroses and ungulate/badger-dispersed fleshy-fruited shrubs was similar between habitats, rabbit/fox- and bird-dispersed species reached 2.7 and 2.0 times higher densities along SLD verges, respectively (Fig. 1).

As we expected, matrix analyses performed with the ADONIS procedure showed that the community structure (species composition and diversity) of both fleshy-fruited shrubs $\left(F_{1,56}=1.66\right.$; $P=0.09)$ and rockroses $\left(F_{1,59}=1.94 ; P=0.11\right)$ did not significantly differ between SLD verges and the scrubland.

\subsection{Size distribution of fleshy-fruited functional groups in relation to SLD}

Considering seedling, saplings and adults altogether, the overall density of fleshy-fruited shrubs was 2.2 times greater along SLD verges than in the scrubland $\left(F_{1,1513}=15.13 ; P<0.001\right)$. However, the relative density of each size class varied between habitats (interaction Habitat*Size class; $F_{2,1513}=3.73 ; P<0.05$ ). The density of seedlings and adults was 5.2 (test of slices; $F_{1,1513}=11.02$; $P<0.001)$ and $1.7\left(F_{1,1513}=3.59 ; P=0.058\right)$ times higher along SLD verges than in the scrubland, respectively, whereas the density of saplings was very similar between both habitats $\left(F_{1,1513}=0.90\right.$; $P=0.342$; Fig. 2).

Nonetheless, while the density of saplings was similar between habitats for every plant functional group (Fig. 2), the differences in the density of seedlings and adults between habitats varied among different plant functional groups. Regarding bird-dispersed species, we found 29.9 times greater seedling density along SLD verges as compared with the scrubland, and a similar density of adult shrubs in both habitats (Fig. 2A). In the case of rabbit/fox-dispersed species, we found 3.2 times and 4.2 times greater seedling and adult densities along SLD verges than in the scrubland, respectively (Fig. 2B). Despite the lack of significant differences for some size classes, the trend of shrub densities was positively related with

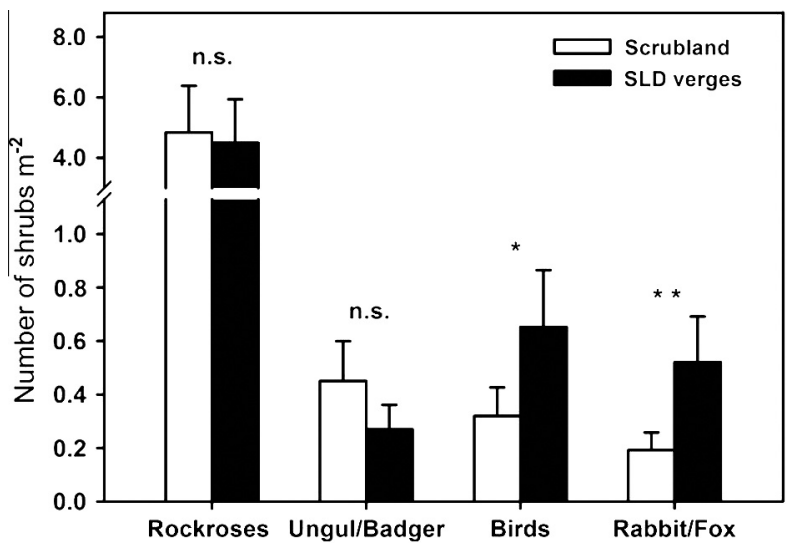

Fig. 1. Differences in the adjusted mean density $( \pm S E)$ of rockroses and fleshyfruited shrubs between habitats. Whereas the density of rockroses and ungulate/ badger-dispersed fleshy-fruited shrubs did not differ between habitats, the density of both bird- and rabbit/fox-dispersed fleshy-fruited shrubs were higher along SLD than in the scrubland. P-values of the corresponding test of slices are shown, indicating whether the differences between habitats were significant (n.s., nonsignificant; $\left.{ }^{*} P<0.05,{ }^{* *} P<0.01\right)$.
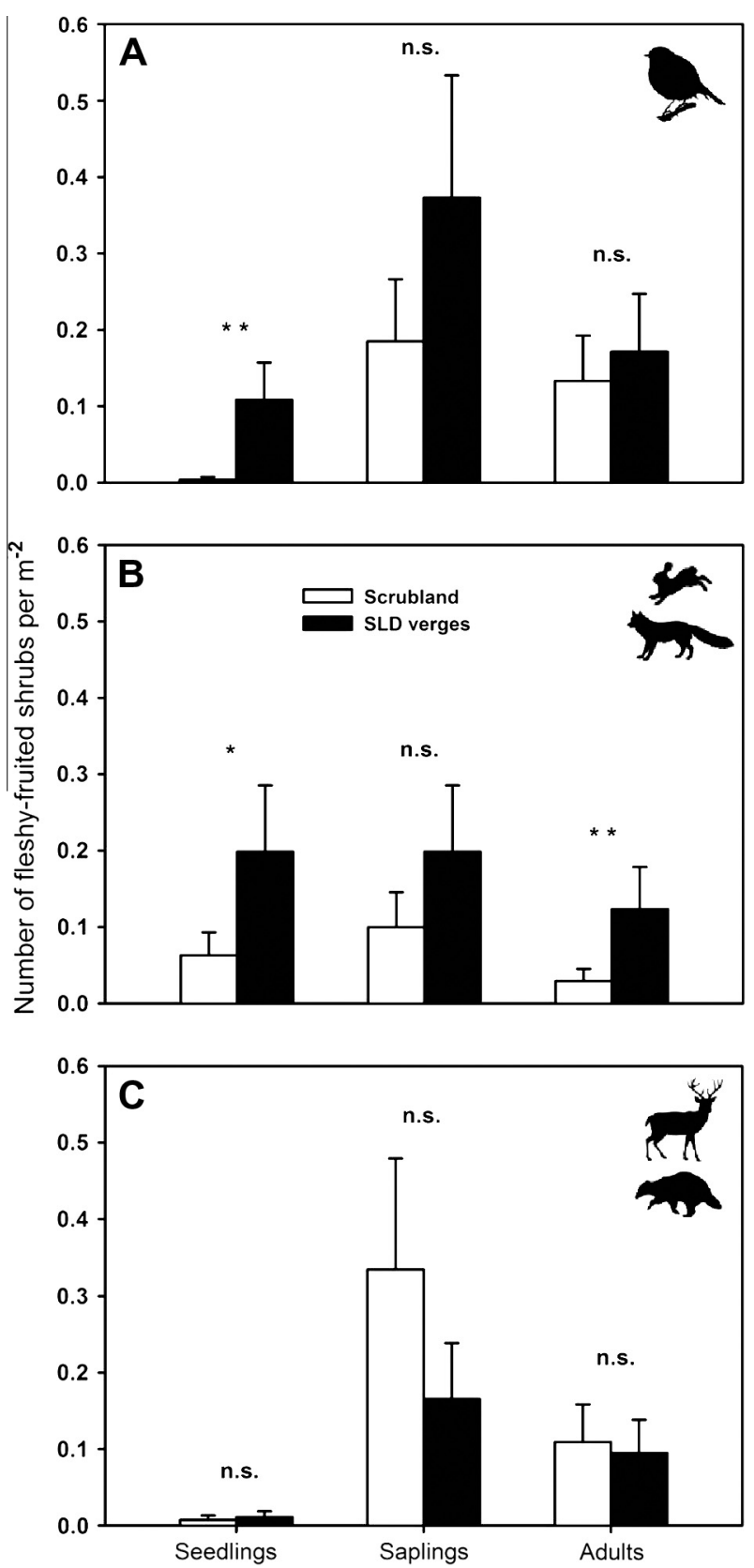

Fig. 2. Differences in the mean density $( \pm S E$ ) of shrub size classes between habitats in the three functional groups of fleshy-fruited shrubs (bird-dispersed, above; rabbit/fox-dispersed, middle; ungulate/badger, below). $P$-values of the differences of least square means are shown, indicating whether the differences between habitats were significant in each case (n.s., non-significant; ${ }^{* *} P<0.01$; ${ }^{* * *-}$ $P<0.0001$ ). Interestingly, rabbit/fox-dispersed fleshy-fruited species appeared in higher densities along SLD verges than in the scrubland either at seedling or adult stage. Thus the presence of SLD is likely promoting their recruitment and establishment.

SLD in both plant functional groups (Fig. 2A and B). However, the absence of differences between habitats in the density of ungulate/badger-dispersed species was consistent for all size classes (Fig. 2C).

\section{Discussion}

Although seed arrival does not guarantee plant recruitment and establishment, it seems to play an important role in determining 
shrub recruitment in relation to SLD in the Doñana area. As expected based on the observed seed rain (Suárez-Esteban et al., 2013), rabbit/fox-dispersed fleshy-fruited shrubs reached greater densitiesalongSLDvergesthanintheadjacentscrubland,whereas rockroses showed similardensities in both habitats. These results add support to the hypothesis that plant community responses to habitatstructurearestrongly influenced by seed dispersalvectors, corroborating evidence from other studies (Damschen et al., 2008; Higginsetal.,2003).

Unexpectedly, we found also higher densities bird-dispersed species along SLD verges than in the scrubland. We suspect this isprobablyrelatedtoamoreintensiveseedraingeneratedbyfrugivorous birds selecting as perches fleshy-fruited shrubs already established along SLD verges, which provide birds with shelter and food resources (Hinsley and Bellamy, 2000). A similar seed reception of bird-dispersed specieshasbeendocumentedinother linear plant formations such as windbreaks (Harvey, 2000) and hedgerows (Pulido-Santacruz and Renjifo, 2011). Contrary to our prediction, ungulate/badger-dispersed shrub densities were similarbetweenhabitats, perhapsbecausebadgeroccursinlowdensities (Fedriani and Delibes, 2009b) and ungulates disperse few viableseedsoflocalfleshy-fruitedshrubs(Pereaetal.,2013;Suárez-Estebanetal.,2013).

Because mammalian and avian frugivores disperse different shrub species, they probably have a complementary and synergic effect on plant recruitment and establishment along SLD verges rather than being functionally redundant (Loiselle et al., 2007). Furthermore, different species within the local mammal community disperse seeds of different shrubs into different habitats (Fedriani et al., 2010; Perea et al., 2013; Suárez-Esteban et al., 2013),promotingplantspatialheterogeneity.Therefore,themaintenance of diverse communities of frugivores is necessary to ensure plant diversity conservation (McConkey et al., 2012; Ozinga etal.,2009)and ecosystem resilience(Loiselle et al.,2007), especially in fragmented landscapes where long-distance dispersal of plants relies on seed rather than on pollen movement(Damschen etal.,2008).

The greater density of seedlings found along SLD verges suggeststhatthesestructurescanbesuitableplacesforshrubrecruitment. However, the overall density of saplings suggests that the proportionofseedlings thatreached thesaplingstagewasgreater inthescrubland(Fig.2).Thiscanbedueeithertoalowerseedling conspicuousnessforherbivoresinthescrublandortohigherseedlingmortality(mainlydrivenbyherbivory,competitionandwater stress during the Mediterranean summer; Kitajima and Fenner, 2005; Tormoetal.,2006),alongSLDverges.Forexample,thepositive selection of SLD by rabbits (Suárez-Esteban et al., 2013) can lead to higher local herbivory pressure on seedlings and thereby highermortality.Indeed, Rostetal.(2012)found thatrabbitspredate large amounts of Mediterranean hackberry ( Celtis australis ) seedlingsinhabitatssimilartoourstudy sites.

On the other hand, considering the density of adult plants, the proportion of saplings that reached the adult stage seemed to be higheralongSLDverges. Thatcouldbeduetoastrongerherbivory pressureonsaplingsbylargeherbivoressuchasdeer,whichavoid SLD (Suárez-Esteban et al., 2013). This hypothesis is consistent with the results of (Cadenasso and Pickett, 2000), showing that meadowvoles( Microtuspennsylvanicus )predate greater amounts of seedlings along forest edges than in forest interiors, whereas white-tailed deer ( Odoleicus virginianus ) feed mainly on saplings within the forest. The relative importance of seedling and sapling predators is known to differ among communities and microhabitats (Kitajima and Fenner, 2005). Thus, beyond seed arrival, the suitabilityofSLDvergesasrecruitmentandestablishmenthabitats willdependalso on theidentityand theabundanceof herbivores, and theirresponsetoSLD.
As expected, we found no differences in the communitystructure of both fleshy-fruited species and rockroses between SLD vergesand theadjacentscrubland.Thisislikelybecauserockroses lack of special dispersal mechanisms, and frugivores visit all kind ofhabitatswithsomeregularityandthusallofthemreceivesome seedsofevery fleshy-fruited shrubspecies.Suchsimilarityinspecies composition and diversity suggest that SLD verges recruit a species pool equivalent to that found in the scrubland, contrary to the patterns detected both along some paved roads (Arévalo etal.,2010)and forestedges(Harperetal.,2005).

Giventhehigherdensityandcomparablespeciesdiversityoffleshy-fruited shrubs along SLD verges as compared with the scrubland, SLD verges (usually considered to be marginal, low-quality habitats)couldyieldpoorlyunderstoodconservationbenefits.Furthermore, thepervasivenessofSLDinalmosteveryterrestrialecosystem gives our findings potentially wide and important applicabilityinvegetationrestorationandconservationprograms.

\subsection{Implicationsforplantconservationandlandscapemanagement}

Planting narrow tree strips is a proper method to favor the maintenance of plant diversity in fragmented landscapes, as well as to control erosion and to soften local microclimate conditions (e.g. wind, temperature, humidity; Harvey, 2000). Conserving highlymobilefrugivoresthatpositivelyselectedSLDvergesforfecal marking (such as rabbits and foxes), and by promoting the growth of native plant recruits, stakeholders can reforest SLD verges without any cost, creating natural hedgerows (i.e. shrub strips). Hedgerows will likely attract seed-dispersing wildlife (HinsleyandBellamy,2000;JohnsonandAdkisson,1985)andcreatefavorablemicroclimateconditionsfortheestablishmentofnew recruits (Harvey, 2000), which boost both seed arrival and plant recruitment (Pulido-Santacruz and Renjifo, 2011), leading to a reforestationfeedback.

ShrubsthatcolonizeSLDvergescanspreadtoadjacenthabitats, especiallythosespeciesdispersedbyhighlymobileanimalvectors (Brudvigetal.,2009).Infarmlands,such"spillover"effectofplants establishedalongSLDhedgerows,whichoftenactasreservoirsand corridors for native plants (Freemark et al., 2002; Wehling and Diekmann, 2009), can accelerate the reforestation of abandoned fields by native species, probably hindering the colonization success of exotics (Standish et al., 2008). This could be particularly importantinsouthernEurope,considering thehighrates offarmland abandonment and consequent risk of exotic plant invasion (Lenda et al., 2012). Furthermore, the diversity of plants in SLD hedgerows may offer habitat and resources for beneficial insects (Mwangi et al., 2012), bats (Fuentes-Montemayor et al., 2011) andbirds(HinsleyandBellamy,2000)thatinturnprovideecosystemservices suchas pollination(Blakeetal.,2012)and pestcontrol(Boylesetal.,2011)inagriculturallands.

In human-dominated landscapes, habitat patches are usually separated by long distances, so plants may be unable to disperse between them, requiring establishment, growthand reproduction within intermediate habitats (Damschen et al., 2008). Given the high density of reproductive fleshy-fruited shrubs found along SLD verges (especially those dispersed by rabbits and foxes), we believe these structures can act as effective corridors for fleshyfruitedshrubs,servingbothasmovementconduitsandasstepping stone habitats for the establishment of new plant populations. In the long term, such intermediate populations can connect otherwise isolated fragments, even boosting the migration of fleshyfruited plants vulnerable to climate change (Hampe, 2011; Jump andPeñuelas,2005).Thatwillimprovegeneflowandmetapopulation dynamics (Leidner and Haddad, 2011), benefiting plant diversity at large scales, such as documented for linear, narrow clear-cuts(Damschenand Brudvig,2012; Damschenetal.,2006). 
Totakeadvantage ofallthedescribed potentialbenefitsofSLD verges holding shrubs, which certainly deserve further research (Haddad and Tewksbury, 2005; Ries etal.,2001), these stripes of habitat must be cautiously managed. Traditional roadside and hedgerow management practices, including periodical mowing and the use of herbicides, are highly unadvisable (Avon et al., 2013). In order to increase shrub abundance, diversity and structural complexity alongSLD verges, we suggest selectively removing undesirable species and to cut only potentially dangerous branches/shrubs rather than using destructive and unselective methods that removeany shrubbycover.

This is the first study documenting the potential role of SLD verges as pervasive hotspots not only for the reception of seeds, butalsofortherecruitmentand theestablishmentofmanyMediterraneanfleshy-fruitedshrubs.AlthoughSLDvergesoccurinhigh densities worldwide and hold a high potential as plant conservation habitats, the extension of these results to larger scales and ecosystemsarecomplicatedbylackofdataandmustproceedwith caution.Beyondseeddispersal,processesinfluencingthedynamics of shrub colonization (e.g. germination, seedling emergence and survival, growth) along SLD verges remain largely unexplored. Long-term comprehensive studies are therefore necessary to understandSLDeffectsoneachstepoftheplantlifecycle,helping ustoclosetheseed dispersalloop(WangandSmith,2002)inhuman-dominated ecosystems. Such essential information would bring stakeholders the opportunity to design and manage SLD moreefficientlywheneverplantconservationandlandscapeforestationeffortsarenecessary.

\section{Acknowledgements}

Weare in debt with Gemma Calvo,PrzemekKurek,Sofía Conradi,M.CarmenRamírezandthestaffofDoñanas'Reservefortheir assistance.WethankDr.PedroJordano,Dr.JoseM.GómezandDr. Daniel García for providing useful discussions. We are sincerely grateful to Dr. Manuela Gonzalez for comments on earlier drafts and for English review, and two anonymous reviewers for useful suggestions that significantly improved the manuscript. The researchwasfinancedbytheSpanishMinisteriodeMedioAmbiente, Rural y Marino (070/2009), Ministerio de Ciencia e Innovación (CGL2010-21926/BOS) and Ministerio deEducación(FPUgrant to A.S.E.;AP2008-01874).

\section{References}

Arévalo, J.R., Otto, R., Escudero, C., Fernández-Lugo, S., Arteaga, M., Delgado, J.D., Fernández-Palacios, J.M., 2010. Do anthropogenic corridors homogenize plant communitiesatalocalscale? AcasestudiedinTenerife(CanaryIslands).Plant Ecol.209,23-35.

Avon,C.,Dumas, Y., Bergès, L., 2013.Managementpracticesincrease theimpactof roads on plantcommunitiesinforests. Biol.Conserv.159,24-31.

Bacles, C.F.E., Lowe, A.J., Ennos, R.A., 2006. Effective seed dispersal across a fragmentedlandscape.Science 311,628.

Bastida,F.,Talavera,S.,2002.Temporalandspatialpatternsofseeddispersalintwo Cistus species(Cistaceae).Ann. Bot.London 89,427-434.

Blake, R.J., Westbury, D.B., Woodcock, B.A., Sutton, P., Potts, S.G., 2012. Enhancement of buffer strips can improve provision of multiple ecosystem services. Outlooks Pest Manage.23,258-262.

Boyles,J.G.,Cryan,P.M.,McCracken,G.F.,Kunz,T.H.,2011.Economicimportanceof batsinagriculture. Science 332,41-42.

Bray, J.R., Curtis, J.T., 1957. An ordination of the upland forest communities of SouthernWisconsin.Ecol.Monogr.27,325-349.

Brederveld,R.J.Jähnig,S.C.,Lorenz,A.W.,Brunzel,S.,Soons,M.B.,2011.Dispersalas alimitingfactorinthecolonizationofrestoredmountainstreamsbyplantsand macroinvertebrates.J.Appl.Ecol.48,1241-1250.

Brudvig, L.A., Damschen, E.I., Tewksbury, J.J., Haddad, N.M., Levey, D.J., 2009. Landscape connectivity promotes plant biodiversity spillover into non-target habitats.Proc.Natl.Acad.Sci.USA106,9328-9332.

Cadenasso,M.L.,Pickett,S.T.A.,2000.Linkingforestedgestructuretoedgefunction: mediation of herbivore damage.J.Ecol.88,31-44.
Damschen, E.I., Brudvig, L.A., 2012. Landscape connectivity strengthens localregional richness relationships in successional plant communities.Ecology 93 , 704-710.

Damschen, E.I., Brudvig, L.A.,Haddad, N.M., Levey, D.J., Orrock,J.L., Tewksbury,J.J., 2008. The movement ecology and dynamics of plant communities in fragmented landscapes.Proc. Natl.Acad.Sci.USA 105,19078-19083.

Damschen,E.I.,Haddad,N.M.,Orrock,J.L.,Tewksbury,J.J.,Levey,D.J.,2006.Corridors increase plantspecies richness atlarge scales.Science 313,1284-1286.

Fedriani, J.M., Delibes, M., 2009a. Functional diversity in fruit-frugivore interactions: a field experiment with Mediterranean mammals. Ecography 32 , 983-992.

Fedriani, J.M., Delibes, M., 2009b. Seed dispersal in the iberian pear,Pyrus bourgaeana: aroleforinfrequent mutualists. Ecoscience 16,311-321.

Fedriani, J.M., Delibes, M., 2011. Dangerous liaisons disperse the mediterranean dwarfpalm:fleshy-pulpdefensiveroleagainstseedpredators.Ecology92,304315

Fedriani,J.M.,Wiegand,T.,Delibes,M.,2010.Spatial patternofadult treesand the mammal-generated seed rainin theIberian pear.Ecography33,545-555.

Fedriani, J.M., Zywiec, M., Delibes, M., 2012. Thieves or mutualists? Pulp feeders enhanceendozoochorelocal recruitment.Ecology93,575-587.

Freemark, K.E., Boutin, C., Keddy, C.J., 2002. Importance of farmland habitats for conservation of plantspecies. Conserv.Biol.16,399-412.

Fuentes-Montemayor,E.,Goulson,D.,Park,K.J.,2011.Pipistrellebatsandtheirprey do not benefit from four widely applied agri-environment management prescriptions. Biol.Conserv.144,2233-2246.

Gómez-Aparicio, L., 2008. Spatial patterns of recruitment in Mediterranean plant species: linking the fate of seeds, seedlings and saplings in heterogeneous landscapesatdifferentscales.J.Ecol.96,1128-1140.

Guzmán, B., Vargas, P., 2009. Long-distance colonization of the Western Mediterranean by Cistus ladanifer (Cistaceae) despite the absence of special dispersalmechanisms.J.Biogeogr.36,954-968.

Haddad, N.M., Tewksbury, J.J., 2005. Low-quality habitat corridors as movement conduitsfor two butterflyspecies.Ecol.Appl.15,250-257.

Hampe, A., 2011. Plants on the move: the role of seed dispersal and initial populationestablishmentforclimate-driven rangeexpansions.Acta Oecol.37, 666-673.

Hampe, A., Garcia-Castaño, J.L., Schupp, E.W., Jordano, P., 2008. Spatio-temporal dynamicsandlocalhotspotsofinitialrecruitmentinvertebrate-dispersedtrees. J.Ecol.96,668-678.

Harper, K.A., Macdonald, S.E., Burton, P. J., Chen, J., Brosofske, K.D., Saunders, S.C. Euskirchen, E.S., Roberts, D.,Jaiteh, M.S., Esseen,P.A., 2005.Edge influence on forest structure and composition in fragmented landscapes. Conserv. Biol. 19 768-782.

Harvey,C.A.,2000.Colonizationofagriculturalwindbreaksbyforesttrees:effectsof connectivity and remnant trees. Ecol.Appl.10,1762-1773.

Herrera,J.M.,García,D.,2009.The role of remnant trees in seed dispersal through the matrix: being alone is notalways sosad. Biol.Conserv.142,149-158.

Higgins, S.I., Nathan, R., Cain, M.L., 2003. Are long-distance dispersal events in plants usually caused by nonstandard means of dispersal? Ecology 84, 19451956.

Hille Ris Lambers, J., Clark, J.S., 2003. Effects of dispersal, shrubs, and densitydependent mortality on seed and seedling distributions in temperate forests. Can.J.ForestRes.33,783-795.

Hinsley,S.A.,Bellamy,P.E.,2000.Theinfluenceofhedgestructure,managementand landscape context on the value of hedgerows to birds: a review. J. Environ. Manage.60,33-49.

Howe, H.F., Miriti, M.N., 2000. No question: seed dispersal matters. Trends Ecol. Evol.15,434-436.

Hulme, P.E., 1997. Post-dispersal seed predation and the establishment of vertebratedispersedplantsinMediterraneanscrublands.Oecologia111,91-98.

Isbell, F., Calcagno, V., Hector, A., Connolly, J., Harpole, W.S., Reich, P.B., SchererLorenzen, M., Schmid, B., Tilman, D., van Ruijven, J., Weigelt, A., Wilsey, B.J., Zavaleta, E.S., Loreau, M., 2011. High plant diversity is needed to maintain ecosystem services. Nature 477,199-202-202.

Johnson, V.C., Adkisson, C.S., 1985. Dispersal of beech nuts by blue jays in fragmentedlandscapes. Am. Midl.Nat.113,319-324

Jordano, P., 1984. Relaciones entre plantas y aves frugívoras en el matorral mediterráneodelárea deDoñana.UniversityofSeville.

Jordano, P., 1995. Angiosperm fleshy fruits and seed dispersers: a comparative analysis of adaptation and constraints in plant-animal interactions. Am. Nat. 145,163-191.

Jump,A.S.,Peñuelas,J.,2005.Runningtostandstill:adaptationandtheresponseof plantstorapid climatechange.Ecol.Lett.8,1010-1020.

Kitajima,K.,Fenner,M.,2005.Ecologyofseedlingregeneration,InSeeds.In:Fenner, M.(Ed.), The Ecology of Regeneration in Plant Communities. CABI Publishing, Wallingford,pp.331-360.

Leidner, A.K., Haddad, N.M., 2011. Combining measures of dispersal to identify conservationstrategiesinfragmentedlandscapes.Conserv.Biol.25,1022-1031.

Lenda,M.,Skórka,P.,Knops,J.M.H.,Moron ‘,D.,Tworek,S.,Woyciechowski,M.,2012. Plant establishment and invasions: An increase in a seed disperser combined withlandabandonmentcausesaninvasionofthenon-nativewalnutineurope. Proc.R.Soc.B-Biol.Sci.279,1491-1497.

Levey, D.J., Bolker, B.M., Tewksbury, J.J., Sargent, S., Haddad, N.M., 2005. Ecology: effectsoflandscapecorridorsonseeddispersalbybirds.Science309,146-148.

Littell, R.C., Milliken, G.A.,Stroup, W.W., Wolfinger, R.D.,Schabenberger, O., 2006. SASforMixed Models, seconded.SASInstituteInc.,Cary,NC. 
Loiselle,B.A.,Blendinger,P.G.,Blake,J.G.,Ryder,T.B.,2007.Ecologicalredundancyin seed dispersal systems: a comparison between manakins (Aves: Pipridae) in twotropical forest, InSeed dispersal.In:Dennis, A.J.,Schupp, E.W.,Green, R.J., Westcott, D.A. (Eds.), Theory and its Application in a Changing World. CAB International,Wallingford,pp.178-199.

Malo,J.E.,Suarez,F.,1996.Cistusladaniferrecruitment-notonlyfire,butalsodeer Acta Oecol.17,55-60.

McConkey, K.R., Prasad, S., Corlett, R.T., Campos-Arceiz, A., Brodie, J.F., Rogers, H., Santamaria,L.,2012.Seed dispersalinchanginglandscapes.Biol.Conserv.146, $1-13$.

Mwangi, D., Kasina, M., Nderitu, J., Hagen, M., Gikungu, M., Kraemer, M., 2012. Diversity and abundance of native bees foraging on hedgerow plants in the Kakamegafarmlands, western Kenya.J.Apicult. Res.51,298-305.

Nathan, R., Katul, G.G., 2005. Foliage shedding in deciduous forests lifts up longdistanceseed dispersal by wind.Proc. Natl.Acad.Sci.USA 102,8251-8256.

Nathan, R., Muller-Landau, H.C., 2000. Spatial patterns of seed dispersal, their determinants and consequences for recruitment. Trends Ecol. Evol. 15, 278285.

Oksanen, J., Blanchet, F.G., Kindt, R., Legendre, P., Minchin, P.R., O'Hara, R.B., Simpson, G.L., Solymos, P., Stevens, M.H.H., Wagner, H., 2012. Vegan: CommunityEcology Package. RPackageVersion 2.0-5.

Ozinga,W.A., Römermann,C.,Bekker,R.M.,Prinzing,A.,Tamis,W.L.M.,Schaminée, J.H.J.,Hennekens, S.M., Thompson, K., Poschlod,P., Kleyer, M., Bakker,J.P.,Van Groenendael, J.M., 2009. Dispersal failure contributes to plant losses in NW Europe.Ecol.Lett. 12,66-74.

Perea, R., Delibes, M., Polko, M., Suárez-Esteban, A., Fedriani, J.M., 2013. Contextdependent fruit-frugivore interactions: partneridentities and spatio-temporal variations. Oikos 122,943-951.

Pulido-Santacruz, P., Renjifo, L.M., 2011. Live fences as tools for biodiversity conservation: a study case with birds and plants.Agroforest. Syst.81,15-30.

Quinn, G.G.P., Keough, M.J., 2002. Experimental Design and Data Analysis for Biologists.CambridgeUniversity Press.

R Development core team, 2012. R: A language and environment for statistical computing.RFoundation forStatistical Computing,Vienna,Austria.
Ries, L.,Debinski,D.M.,Wieland,M.L.,2001.Conservationvalue ofroadsideprairie restoration tobutterfly communities.Conserv.Biol.15,401-411.

Rost,J.,Pons,P.,Bas,J.M.,2012.Seeddispersalbycarnivorousmammalsintoburnt forests: an opportunity for non-indigenous and cultivated plant species. Basic Appl.Ecol.13,623-630.

Russo,S.E., Portnoy,S., Augspurger,C.K., 2006. Incorporating animal behavior into seed dispersalmodels:implications forseed shadows.Ecology 87,3160-3174.

Sagnard, F., Pichot, C., Dreyfus, P., Jordano, P., Fady, B., 2007. Modelling seed dispersal to predict seedling recruitment: recolonization dynamics in a plantation forest.Ecol.Model.203,464-474.

Schlaepfer, M.A., Runge, M.C., Sherman, P.W., 2002. Ecological and evolutionary traps. TrendsEcol.Evol.17,474-480.

Shiels, A.B., Walker, L.R., 2003. Bird perches increase forest seeds on Puerto Rican landslides. Restor.Ecol.11,457-465.

Spiegel, O., Nathan, R., 2010. Incorporating density dependence into the directeddispersal hypothesis.Ecology91,1538-1548.

Standish,R.J.,Cramer,V.A.,Hobbs,R.J.,2008.Land-uselegacyandthepersistenceof invasive Avena barbata on abandoned farmland.J.Appl.Ecol.45,1576-1583.

Suárez-Esteban, A., Delibes, M., Fedriani, J.M., 2013. Barriers or corridors? The overlooked role of unpaved roads in endozoochorous seed dispersal. J. Appl. Ecol.50,767-774.

Tewksbury, J.J., Levey, D.J., Haddad, N.M., Sargent, S., Orrock, J.L., Weldon, A. Danielson, B.J., Brinkerhoff, J., Damschen, E.I., Townsend, P., 2002. Corridors affect plants, animals, and their interactions in fragmented landscapes. Proc. Natl.Acad.Sci.USA99,12923-12926.

Tormo,J., Bochet, E., García-Fayos, P., 2006. Is seed availability enough to ensure colonization success? An experimental study in road embankments. Ecol.Eng. 26,224-230.

Wang,B.C.,Smith,T.B.,2002.Closingtheseeddispersalloop.TrendsEcol.Evol.17, 379-385.

Wehling,S.,Diekmann,M.,2009.Importanceofhedgerowsashabitatcorridorsfor forest plants inagriculturallandscapes. Biol.Conserv.142,2522-2530.

Wenny, D.G., 2001. Advantages of seed dispersal: a re-evaluation of directed dispersal.Evol.Ecol.Res.3,51-74. 